\title{
PerCursos
}

\section{Formação do professor de geografia na produção do material didático sobre o território goiano}

\section{Resumo}

$\mathrm{Na}$ formação do professor, os conhecimentos em Didática constituem pilar importante às ações acadêmicas a respeito desse campo e são capazes de ampliar as teorias, atualizar conceitos, estabelecer críticas às formulações incompatíveis com os contextos escolares, além de orientar as práticas de ensino específicas dos seus conteúdos. Nessa perspectiva, a discussão deste artigo emerge do projeto "Conteúdos Geográficos nas escalas local/regional no contexto do Exame Nacional do Ensino Médio (Enem)", na Universidade Federal de Goiás, financiado pelo Conselho Nacional de Desenvolvimento Científico e Tecnológico (CNPq). O objetivo é relacionar as potencialidades da investigação crítico-colaborativa na formação dos professores de Geografia e na produção do material didático sobre a relação cidade-campo em Goiás. Como metodologia, privilegiou-se a colaboração entre pesquisadores, professores e estudantes de Geografia para transformar o mundo da prática. Nessa investigação, a voz e a perspectiva dos sujeitos envolvidos são consideradas como parte da investigação e contribuem para a produção do conhecimento ao longo do processo. Nesse contexto, a elaboração do material didático envolveu as etapas de: definição do tema por meio de problematizações; investigação sobre a produção científica do conteúdo; recontextualização do conhecimento para a escala regional e para os objetivos escolares; experimentação e avaliação do material no Ensino Médio. A pesquisa colaborativa efetivou-se na produção didática sobre a relação cidade-campo em Goiás e, nesse conjunto de ações, permitiu-se aos participantes um conhecimento mais autoral no próprio processo de formação inicial e continuada e o desenvolvimento de metodologias com o protagonismo dos sujeitos.

Palavras-chave: Professores de geografia. Ensino - Metodologia. Professores - formação. Didática. Metodologias de ensino.

\section{Lana de Souza Cavalcanti}

Doutora em Geografia pela

Universidade de São Paulo - USP.

Pós-doutora em Geografia pela

Universidade Complutense de

Madrid/Espanha. Professora da

Universidade Federal de Goiás-

UFG.

Brasil

Is.cavalcanti@gmail.com.br

\section{Marquiana de Freitas Vilas Boas Gomes}

Doutora em Geografia pela

Universidade Estadual Paulista UNESP. Pós-doutora em

Geografia pela UFG. Professora

Associada pela Universidade

Estadual do Centro-Oeste -

UNICENTRO.

Brasil

marquiana@unicentro.br

\section{Vanilton Camilo de Souza}

Doutor em Geografia pela

Universidade Federal de Goiás -

UFG. Professor da Universidade

Federal de Goiás-UFG. Pós-doutor

em Geografia pela USP.

Brasil

souzavanilton@gmail.com

\section{Para citar este artigo:}

CAVALCANTI, Lana de Souza; GOMES, Marquiana de Freitas Vilas Boas; SOUZA, Vanilton Camilo de. Formação do professor de geografia na produção do material didático sobre o território goiano. Revista PerCursos, Florianópolis, v. 21, n.46, p. 301 -325, maio/ago. 2020.

DOI: $10.5965 / 1984724621462020301$

http://dx.doi.org/10.5965/1984724621462020301 


\title{
Geography teacher training in the production of the didactic material about the goiás territory
}

\begin{abstract}
11- In teacher education, didactic knowledge is an important pillar of academic actions in this field. It can broaden theories, updating concepts, establishing criticisms of formulations incompatible with school contexts, and guiding the specific teaching practices of their contents. In this perspective, the discussion of this article emerges from the project "Geographical Contents on the local/regional scales in the context of the National High School Exam (Enem)", at the Federal University of Goiás, financed by the National Council for Scientific and Technological Development (CNPq). The objective is to relate the potential of criticalcollaborative research in Geography teachers' training and the production of didactic material on the citycountryside relationship in Goiás. As a methodology, the collaboration between Geography researchers, teachers, and students was privileged to transform the world of practice. In this investigation, the voice and perspective of the subjects involved are considered as part of the investigation and contribute to the production of knowledge throughout the process. In this context, the preparation of didactic material involved the steps of: defining the theme through problematizations; research on the scientific production of content; recontextualization of knowledge for the regional scale and school objectives; experimentation, and evaluation of material in high school. The collaborative research was carried out in the didactic production about the city-countryside relationship in Goiás. In this set of actions, the participants were allowed more authorial knowledge in the very process of initial and continued training and the development of methodologies with the protagonism of the subjects.
\end{abstract}

Keywords: Geography teachers. Teaching methodology. Teachers - training. Didactic. Teaching methodologies. 


\section{Introdução}

Na formação do professor, os conhecimentos sobre Didática constituem pilar importante às ações acadêmicas nesse campo e são capazes de ampliar as teorias, atualizar conceitos, estabelecer críticas às formulações incompatíveis com os contextos escolares, além de orientar as práticas de ensino específicas dos seus conteúdos. O trabalho que ora se apresenta, vincula-se a essa perspectiva do desenvolvimento da Didática na Formação de Professores de Geografia. A discussão emerge do projeto de pesquisa Conteúdos Geográficos nas escalas local/regional no contexto do Exame Nacional do Ensino Médio (Enem), na Universidade Federal de Goiás-UFG, financiado pelo Conselho Nacional de Desenvolvimento Científico e Tecnológico - CNPq, período 2017-2020 (Brasil).

Os objetivos são analisar as potencialidades da investigação crítico-colaborativa na formação de professores e na produção de materiais didáticos sobre Goiás, na escala local/regional, tendo como sujeitos desse processo os professores da universidade, os professores da Educação Básica, os alunos da graduação e da pós-graduação em Geografia. As análises centram-se na contribuição de investigação dessa natureza na transformação do mundo da prática e na formação dos professores em Geografia ao participarem da elaboração do Material Didático para os estudos regionais e locais.

No cenário escolar, atribui-se ao professor a função de articular os conceitos e conteúdos geográficos com o cotidiano do aluno (CAVALCANTI, 2012). Contudo, nem sempre é possível ao professor desempenhar satisfatoriamente esse papel, tendo em vista a ausência de materiais didáticos adequados. Dessa realidade, emerge a importância da elaboração de materiais didáticos que contemplem conteúdos sobre Goiás, com ênfase sobre a cidade, linha de trabalho da Rede de Pesquisa em Ensino de Cidade (REPEC), rede responsável por essa tarefa investigativa.

A REPEC é formada por professores e pesquisadores da UFG, da Pontifícia Universidade Católica - PUC e das secretarias de estado de Goiás e do município de Goiânia. A rede objetiva prover o professor de material que o auxilie a trabalhar com conteúdos geográficos de maneira articulada com a espacialidade local/regional dos alunos; oferecer espaço de formação inicial e continuada com vistas ao entendimento 
teórico-metodológico de uma Geografia que faça sentido na escola, via aprendizagem orientada pelo conhecimento geográfico e pelas práticas cidadãs desde a escola; demonstrar que o conhecimento sobre a Geografia Escolar é mais significativo e autônomo quando efetivado colaborativamente. Para o alcance desses objetivos, pressupõe-se contribuir com condições para ação protagonista do professor de Geografia. A produção do material didático sobre a relação campo/cidade no território goiano ${ }^{1}$ (2020) é parte desse processo e constitutivo dos objetivos deste artigo.

Outro aspecto importante da REPEC tem a ver com a efetiva vinculação dessa rede de pesquisa com professores de Geografia da Educação Básica da Rede Pública na elaboração dos materiais didáticos, organizados na forma de fascículos. Esses profissionais atuam colaborativamente em distintas etapas de sua produção. Um grupo participa do processo, como integrantes da equipe, na concepção e na escrita do material. Outro grupo atua como leitores críticos e experimentam o material didático na sala de aula e, posteriormente, apontam sugestões para o seu aprimoramento.

Neste artigo, por meio da socialização do processo de experimentação e avaliação do material didático, com o envolvimento dos professores da educação básica e dos alunos da graduação e da pós-graduação, analisou-se as contribuições desse processo para a sua formação (inicial e continuada). Foram destacados, nesse sentido, o processo formativo profissional e os estudos efetivados sobre a escala regional e local na relação cidade-campo em Goiás.

O texto está organizado em três partes. Na primeira, apresenta-se a compreensão do lugar da Didática na formação dos professores e como esse campo fundamenta as ações investigativas e as ações didáticas. Na segunda parte, detalham-se os procedimentos metodológicos da pesquisa, com os diferentes sujeitos participantes do projeto e as dimensões importantes da ação colaborativa na produção do material. $\mathrm{Na}$ terceira e última parte, são apresentadas a avaliação das ações colaborativas e sua contribuição à formação dos professores de diferentes níveis formativos.

\footnotetext{
${ }^{1}$ O material está na $3^{\mathrm{a}}$. edição, publicada em 2019.
} 


\section{O lugar da didática na formação de professores}

Em que consiste uma formação do professor que possibilite o desenvolvimento, ao longo de sua carreira, de um protagonismo docente? Que relação se estabelece entre ela, o conhecimento escolar da disciplina e o seu ensino?

Entre aspectos necessários ao desenvolvimento do protagonismo docente, considera-se a boa formação profissional e a autonomia na realização das funções escolares, essencialmente as de ensinar os conteúdos da disciplina na sala de aula. A formação profissional com essa potencialidade pressupõe uma base teóricometodológica que, por um lado, ofereça os elementos para que o professor supere os limites de ações sem reflexão, tenha como base os conteúdos contextualizados e as aprendizagens com significado para os alunos. Por outro lado, considera-se que essa formação seja capaz de explicitar as dimensões do conhecimento didático de conteúdo e de contexto (SHULMAN, 2005).

Mas como construir essa base teórico-metodológica, nessa perspectiva da formação docente? Várias ações podem contribuir para alcançar esse objetivo e, dentre elas, a pesquisa apresenta-se como um bom caminho formativo. E, especificamente, o artigo explora esse caminho: a reflexão sobre a investigação crítico-colaborativa, com o envolvimento de professores da universidade e da escola e alunos em formação inicial, pode potencializar tais dimensões do conhecimento didático.

Atuando justamente nesse caminho formativo, a proposta da REPEC, a qual está vinculado o projeto analisado no presente artigo, é formar professores engajados na necessidade de tomar a realidade escolar como aspecto relevante em seu próprio processo de desenvolvimento e com atividades investigativas que se referenciem pelos conhecimentos específicos da disciplina científica, nesse caso a Geografia, e da educação como fundamentos para o desenvolvimento didático da área.

Compreende-se que esse processo de formação do professor é mais compatível com a ideia de produção de conhecimento voltado ao seu protagonismo. Essa produção, por sua vez, contribui para uma atuação crítica e reflexiva na escola, considerada como 
dimensão complexa da realidade social, cultural e ambiental (CUNHA, 2010; IMBERNÓN, 2017; LUDKE, 2001). Nessa perspectiva,

Todos y cada uno de los estudios que ofrece esta propuesta curricular intentan de alguna manera acercar ao maestro investigador las herramientas básicas para que pueda construir su propio conocimiento profesional deseable. Este proceso de formación individual y compartida no representa sin embargo un estadio final e que confiere al profesor la condición de investigador escolar, sino que esta se va adquiriendo progresivamente en el desarrollo profesional con el estudio, el trabajo en equipo y la práctica docente. No es por tanto atributo de la experiencia, pues sabemos que a veces a rutina sin reflexión y estúdio, por muchos años que se practique, no gera nada más que eso, rutina. (TRAVÉ; CAÑAL; POZUELO, 2003, p. 12 -13)

Nessa proposta, a compreensão da formação do professor busca superar as perspectivas academicistas, distanciadas da realidade escolar, para uma formação centrada em sua muldimensionalidade, com forte peso na sua formação teóricoconceitual e na reflexão teórica sobre sua prática. Essa concepção está apoiada em García Pérez (2006) quanto à dimensão estrutural e dinâmica inerente ao conhecimento profissional. Para o autor, o conhecimento do professor é constituído por diversas fontes, dentre as quais, o saber prático da profissão. Segundo ele,

[...] podemos decir que este saber práctico está constituido por un conjunto de «teorías prácticas», organizadas en torno a cuestiones del tipo: finalidades de la educación y sentido de la escuela, naturaleza del conocimiento escolar, hipótesis sobre el proceso de construcción y seguimiento de dicho conocimiento, etc. Estas teorías habrán de ir generándose a través del contraste, la integración y la reconstrucción de contenidos formativos procedentes de diferentes fuentes, en un proceso que iría transformando el pensamiento práctico profesional simplificador en un pensamiento práctico enriquecido de carácter complejo; [...] (GARCÍA PÉREZ, 2006, p. 282)

Sobre as duas dimensões desse conhecimento, a estrutural e a dinâmica, García Pérez (2006) argumenta que elas ocorrem concomitantemente e estão inter- 
relacionadas. A dimensão estrutural do conhecimento profissional do professor é composta pelo conhecimento metadisciplinar, e as didáticas, por exemplo (GARCíA PÉREZ, 2000, 2006; PÓRLAN; RIVERO, 1998). O conhecimento metadisciplinar, apesar de generalista, pode gerar efeitos diretos sobre a prática de ensino; por exemplo, permitir algumas relações com os conteúdos curriculares. Às didáticas específicas atribui-se o papel central na formação de um saber profissional desejável. A elas caberá a articulação dos diversos níveis do conhecimento: disciplinar, curricular, profissional, dentre outros, para, então, produzir um conhecimento próprio e estratégico para e sobre a escola, no sentido de transformar o modelo tradicional de ensino predominante.

Desse modo, a didática específica não será referência apenas para o processo de aprendizagem dos alunos. Ela é, também, condição básica para a formação do professor, principalmente, para a construção de um conhecimento profissional para o ensino e sobre a investigação escolar do campo disciplinar, além de proporcionar os fundamentos teórico-metodológicos para os encaminhamentos dos conteúdos na sala de aula. Ou seja, afirma-se, com base em Shulman (2005), que os conteúdos geográficos na sala de aula efetivam-se, de um lado, pelo conhecimento da disciplina (Geografia) e, por outro lado, pelos conhecimentos pedagógicos (didática, planejamento de ensino, dos processos de aprendizagem, da avaliação).

Nessa linha, Cavalcanti (2006, p. 32) aponta que a tarefa principal do professor é ensinar aos seus alunos conteúdos relevantes para que possam compreender o espaço em que vivem. A autora ressalta, no entanto, que, mais do que ensinar os conteúdos, "é necessário também ensinar-lhes modos de pensamento e ação" próprios da Geografia. Esses modos de pensamento estão intrinsecamente vinculados aos conceitos estruturantes da ciência e são eles que possibilitam a mediação didática do professor nos processos de aprendizagens dos alunos, pois proporcionam um modo de pensar próprio da matéria no contexto da sala de aula e constituem-se em elementos importantes na constituição da Geografia Escolar.

A partir desse entendimento, tem-se que essa Geografia é fundamental, pois permite ao aluno não só fazer uma leitura mais clara da sua realidade e de outras, mas também exercitar seu direito de interferir na organização espacial. Isso implica, portanto, 
a necessidade de o ensino da Geografia fundamentar-se em um corpo teóricometodológico baseado em conceitos e temáticas que compõem o conhecimento geográfico, os quais devem ser problematizados e contextualizados, de forma a tornarem a aprendizagem significativa. E para que a compreensão de mundo seja significativa, é preciso considerar os conhecimentos prévios dos alunos e o meio geográfico no qual eles estão inseridos. Essas são dimensões fundantes do lugar que a Didática da Geografia ocupa na formação e na prática do professor, enquanto profissional autônomo e capaz de exercer uma ação protagonista na Geografia Escolar.

Esses aspectos da relação entre a Didática da Geografia e a investigação colaborativa foram fundamentais na produção do material didático da REPEC, por pressupor que a ação investigativa potencializará a formação dos envolvidos, com a participação nas atividades da pesquisa e nas discussões, problematizações, dúvidas e superações nas quais tanto o professor quanto os alunos são protagonistas na construção do conhecimento inerente à sua profissão, tornando-os mais autônomos quanto à sua tarefa principal: ensinar Geografia na sala de aula.

\section{A pesquisa-ação crítico-colaborativa na produção do material didático e na formação do professor de Geografia}

A pesquisa-ação crítico-colaborativa tem origem na demanda de um grupo de professores que buscam a colaboração de um pesquisador para transformar o mundo da prática, visando à formação de qualidade dos docentes e o seu protagonismo no ensino. Nessa modalidade de pesquisa, a voz e a perspectiva dos sujeitos envolvidos são consideradas como parte da metodologia da investigação, que, por sua vez, se organiza pelas situações relevantes que emergem do processo.

Nesse tipo de pesquisa, o pesquisador da universidade deve assumir dois papéis complementares: o de pesquisador e o de participante do grupo. Cabe a ele auxiliar o grupo na problematização e na localização das teorias capazes de ampliar a consciência dos envolvidos. Isso decorre do fato de que a pesquisa colaborativa "é atividade de coprodução de conhecimentos e de formação em que os pares colaboram entre si com o 
objetivo de resolver conjuntamente problemas que afligem a educação" (IBIAPINA, 2008, p. 25). Outro aspecto a considerar é que, nessa modalidade, o professor, ao investigar sua ação, também está em processo formativo (FRANCO, 2010).

Considerando que nessa ação da REPEC o objetivo da pesquisa-ação colaborativa foi de elaborar materiais didáticos de conteúdo geográfico e, simultaneamente, desencadear experiências formativas na elaboração desses materiais, buscou-se também: promover a aproximação dos professores de Geografia do ensino médio com a universidade; conhecer e discutir as demandas e os desafios da atuação profissional dos professores da educação básica; problematizar as práticas e encontrar alternativas para superar as dificuldades de ensinar a geografia de Goiás no ensino médio.

Na pesquisa se desenvolveu a análise dos documentos oficiais que regem o ensino médio e dos instrumentos avaliativos do Enem; e as seguintes etapas na produção do material didático: (1) constituição do grupo focal para definição de suas temáticas; (2) pesquisa bibliográfica para sua elaboração; (3) elaboração; (4) experimentação e avaliação. Contudo, alguns acadêmicos participaram apenas da elaboração do material, assim como parte dos professores da educação básica participaram somente da sua experimentação e avaliação.

Dessas etapas, ressalta-se que, na elaboração do material didático, definiu-se o tema por meio de problematizações e do grupo focal; investigou-se sobre a produção científica referente a esse tema; e recontextualizou-se o conhecimento para a escala regional e para os objetivos escolares. Na experimentação, os professores do ensino médio utilizaram na sala de aula uma versão preliminar do material didático, diagnosticando suas potencialidades didáticas. E, na avaliação, por meio de um seminário e um questionário, refletiu-se sobre o trabalho realizado.

O seminário foi organizado em dois momentos. No primeiro, os estudantes e professores do ensino médio apresentaram os resultados das ações com o uso do material didático e, no segundo momento, no formato de roda de conversa, ouviram-se professores da educação básica e pesquisadores da REPEC (no total de 18 participantes) sobre as contribuições do material didático na relação ensino-aprendizagem. 0 
questionário foi respondido em plataforma online por parte dos sujeitos envolvidos no processo (total de 9 respondentes, sendo: 4 estudantes de graduação, 2 estudantes da pós-graduação, 2 professores universitários e 1 professor da educação básica).

Na sequência deste artigo, articula-se a experiência do processo de produção do material didático aos resultados da avaliação para problematizar o potencial desta ação colaborativa para a formação inicial e contínua dos professores envolvidos.

\section{A formação do professor na produção colaborativa de materiais didáticos sobre a relação cidade-campo}

A produção colaborativa do material didático foi um importante exercício de estudo, reflexão e escrita, assim como a avaliação do material produzido e de sua experimentação na sala de aula constituiu-se num interessante processo formativo. Sobre esse processo, vale destacar alguns aspectos, dentre eles: 1) a sistematização de uma abordagem geográfica do tema. Para tanto, recorremos às frequentes perguntas relacionadas às compreensões geográficas: Onde? Por que nesse lugar? Por que aqui e não em outro lugar? Como? Por quê? Para quê? Quando?; 2) a utilização das pesquisas desenvolvidas no IESA/UFG sobre o Estado de Goiás como referências para abordar geograficamente o tema; 3) o estabelecimento de que os saberes espaciais do cotidiano dos alunos são referências para ensinar Geografia; 4) a elaboração de atividades (exercícios) que propiciassem ação cognitiva com vistas ao desenvolvimento de um pensamento geográfico e, 5) a avaliação e reelaboração do texto a partir de pareceres de especialistas e de professores da escola.

O material didático contém uma estrutura que não se coaduna com o ensino baseado na transmissão dos conteúdos, assim apresentada: no início da seção, o texto busca problematizar e motivar o aluno a pensar no tema que está sendo abordado, bem como priorizar a representação e a ilustração dos lugares que estão sendo estudados. Em seguida, o texto apresenta a sistematização do conteúdo da Geografia e a sua ampliação. Ao final da seção, o objetivo é recapitular o que foi apreendido, bem como possibilitar ao 
aluno associações entre o conhecimento e a realidade como dimensões que se entrecruzam para perceber, compreender e agir no seu dia a dia.

Ressalta-se que o material didático sobre $A$ relação cidade/campo no território goiano (figura 01) é parte de um conjunto de fascículos didáticos temáticos elaborados pela REPEC. Os temas apresentados nesse material didático são abordados de modo a possibilitar a construção de conhecimentos dos alunos, com atividades problematizadoras voltadas para o seu cotidiano, para seu lugar de vivência mais imediato, ao mesmo tempo em que procura fornecer fatos e conhecimentos sistematizados sobre o estado de Goiás.

Figura 01 - Seções temáticas do material didático

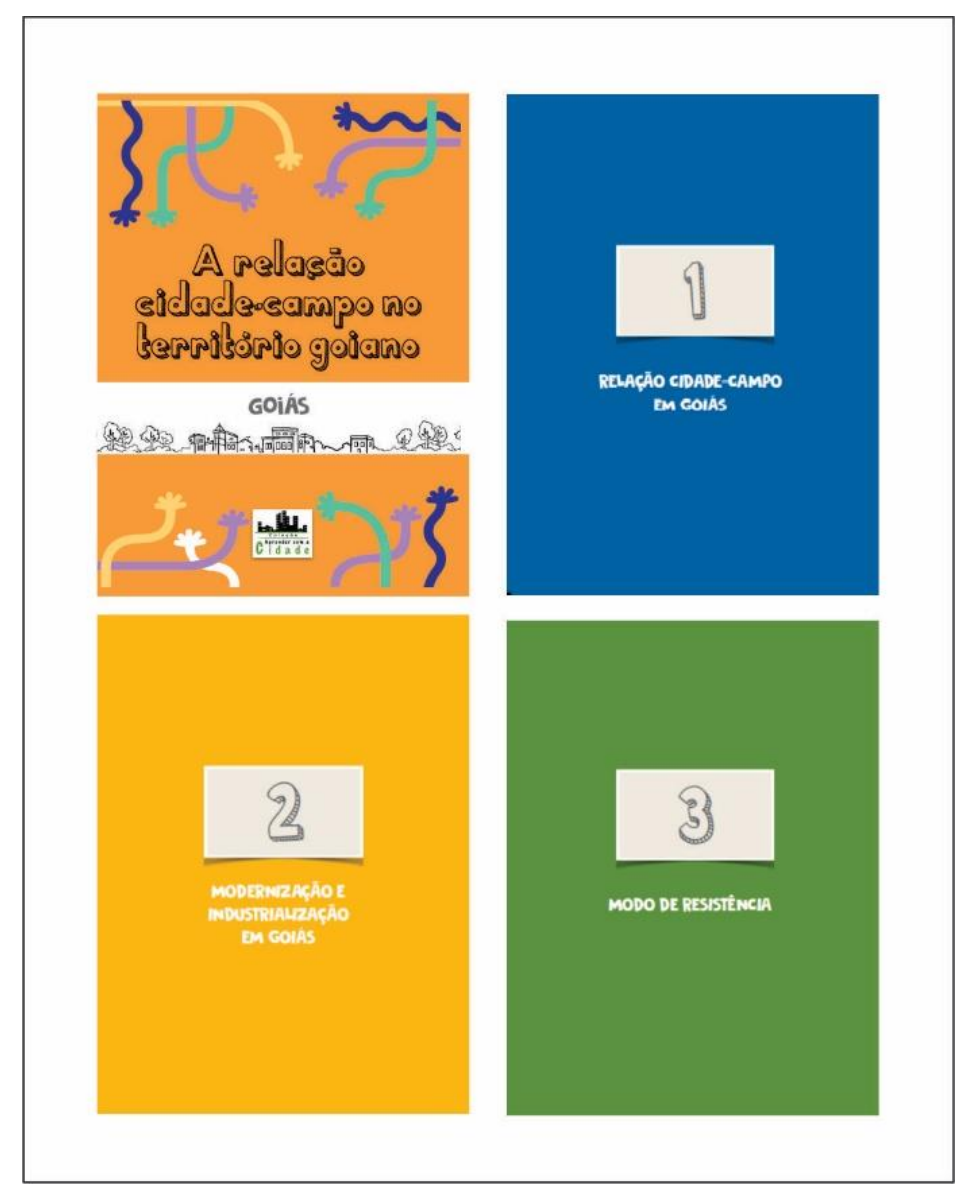

Fonte: Cavalcanti; Oliveira; Spironello (2020). 
O material didático possui 64 páginas, distribuídas em três seções. Na primeira, intitulada A relação cidade/campo no território goiano, abordam-se conceitos como campo e cidade e a relação entre esses dois espaços, assim como se problematizam o uso e a ocupação do solo no estado de Goiás. Na segunda, Modernização e industrialização em Goiás, contextualizam-se as atividades desenvolvidas no campo e em cada mesorregião do estado, além do processo de modernização, de acordo com as atividades realizadas. Na terceira, intitulada Modos de resistência, problematiza-se o conceito de grupos de resistência no território goiano, no contexto de concentração de terras. Os textos são acompanhados de atividades que exploram diferentes linguagens (figura 02) como mapas, imagens orbitais, filmes, textos complementares. Incentiva-se também o uso de geotecnologias e de questões do Exame Nacional do Ensino Médio.

Figura 02 - Exemplos de imagens para leitura, interpretação e análise no material didático

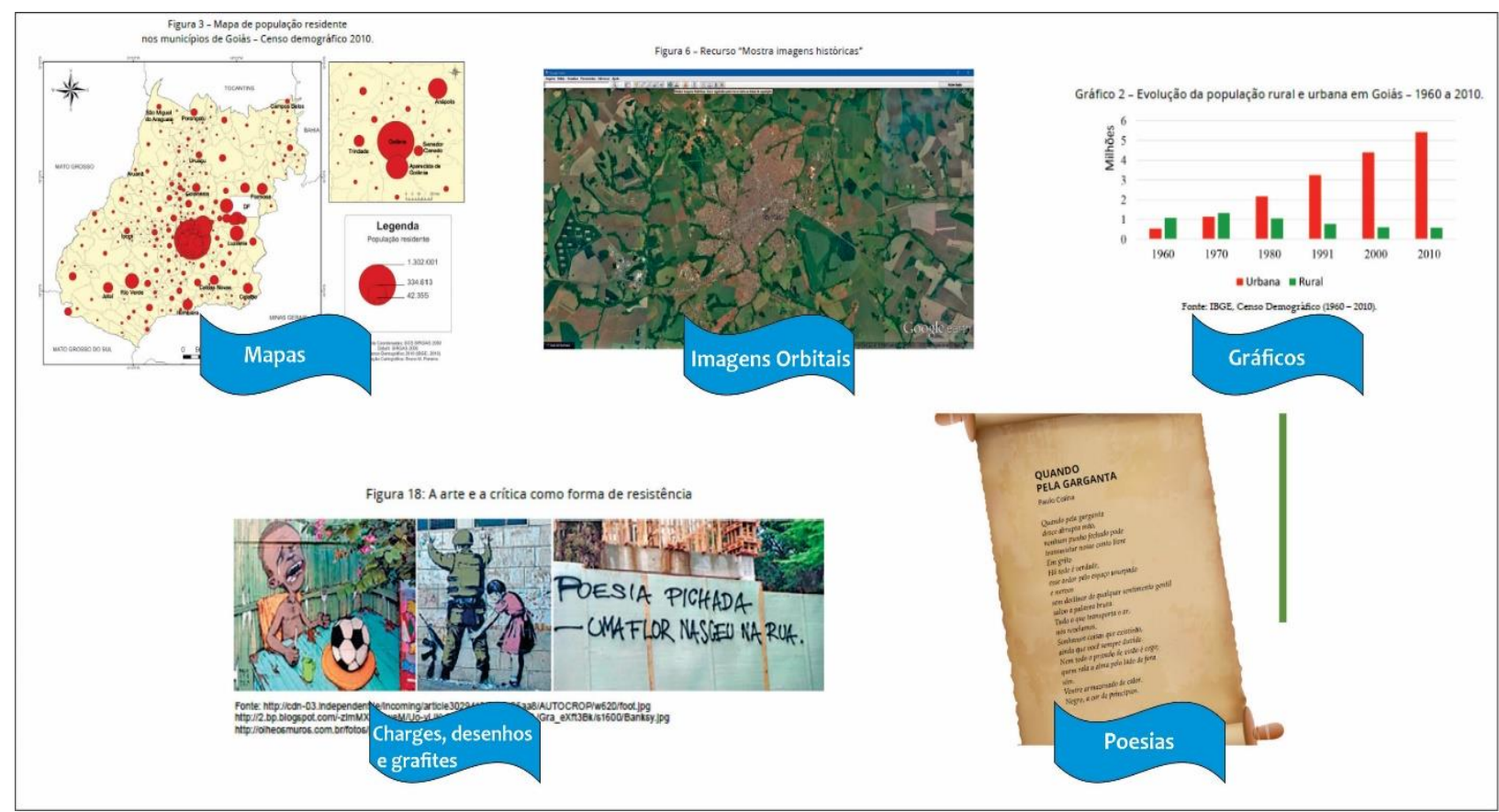

Fonte: Cavalcanti; Oliveira; Spironello (2020).

Para cada seção há cinco partes ou subseções (figura 03), que convidam o leitor a interagir com o texto. Estas partes são denominadas: 1 - Converse Comigo: parte do texto 
que busca problematizar e motivar o aluno a pensar no tema que está sendo abordado; 2 - Traços e Retratos: parte que tem como propósito priorizar a representação e a ilustração dos lugares que estão sendo mencionados, estudados; 3 - Mergulhando no Tema: parte do texto destinada à sistematização do conteúdo e à sua ampliação; 4 - O que foi que eu aprendi mesmo: parte que objetiva recapitular e sistematizar o conteúdo e os conhecimentos ensinados; e 5 - Antenado com a Realidade: momento destinado para possibilitar ao aluno associar os conteúdos estudados com a sua realidade cotidiana.

Figura 03 - Exemplo de atividades de proposição de interação do estudante com o material

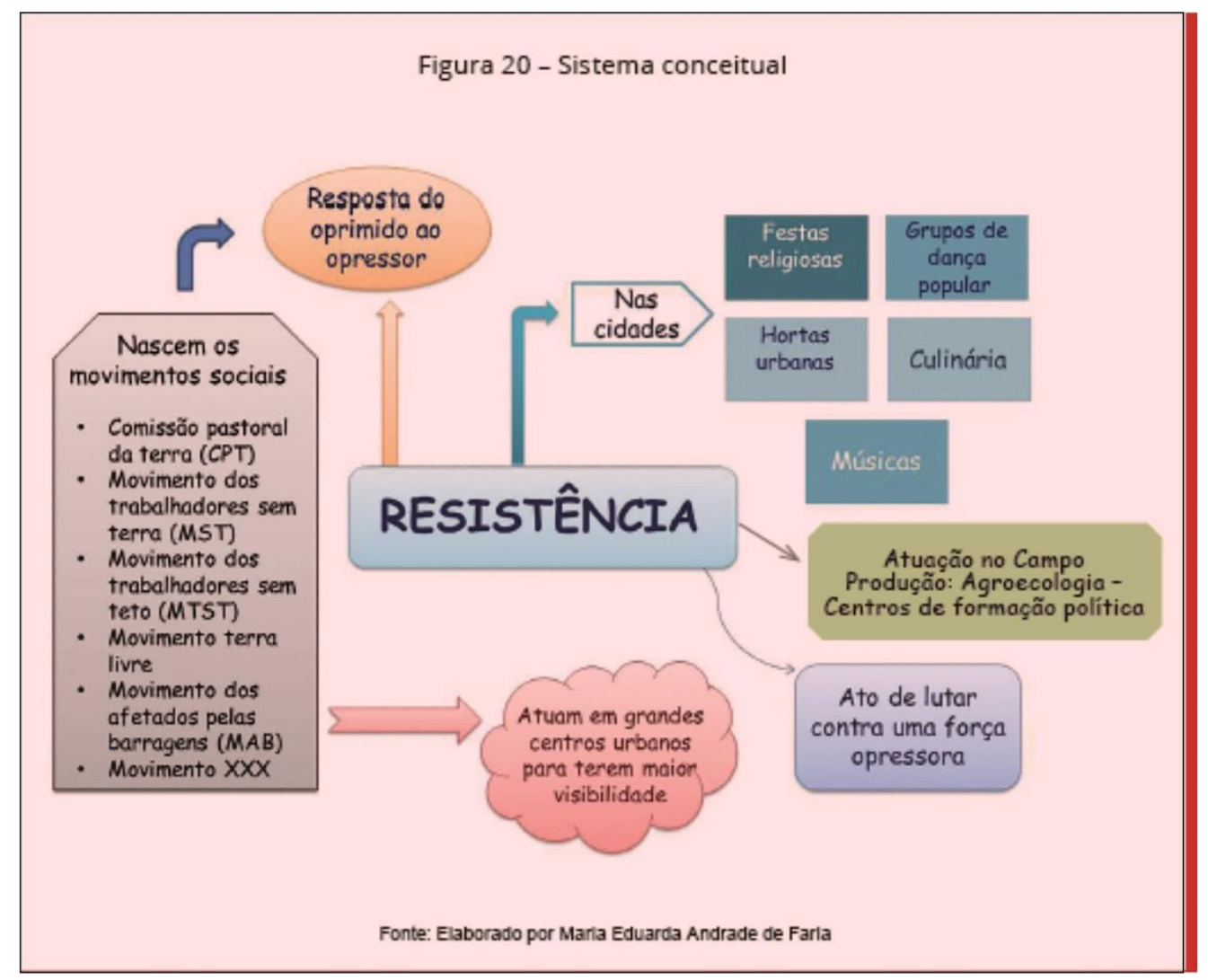

Fonte: Cavalcanti; Oliveira; Spironello (2020).

A linguagem do material didático é dialógica, buscando interagir com o estudante por meio de situações-problema. Embora rico em dados apresentados nos textos, 
tabelas, gráficos, mapas e fotos, há proposições para consulta em base de dados em instituições, a exemplo do mapa interativo disponível no site do Laboratório de Processamento de Imagens e Geoprocessamento (LAPIG/UFG)2; e o Sistema Estadual de Geoinformação de Goiás (SIEG)3 - As orientações também relacionadas a como manipular o Google Maps e o Street View estão em várias seções do material didático.

Desse modo, o estudante pode buscar as informações e fazer suas próprias análises, mas também há uma orientação de como acessar essas plataformas. E, para alguns conceitos e nomenclaturas específicas, o material também dispõe de um glossário, com definições e esclarecimentos que estão disponíveis em caixas de texto.

$\mathrm{Na}$ avaliação do material, verificou-se que há convergência entre os professores da educação básica quanto à contribuição do material didático na produção de conhecimento sobre a escala local, com a contextualização da realidade dos estudantes, a interdependência entre o rural e o urbano, a diversidade de informações sobre Goiás, assim como a valorização da cultura e dos movimentos de resistência. Como descreve um dos professores:

Por muito tempo, nós trabalhamos uma geografia numa perspectiva eurocêntrica, ou também, por muito tempo, uma geografia de São Paulo, ou de outras regiões brasileiras, e, então, colocar a Geografia de Goiás em pauta, o território goiano em pauta, faz a gente entender muito as nossas dinâmicas, nossos dilemas, o que nos aproxima dos outros espaços, e o que nos distancia também. [...]. E esse ensino de Geografia já desperta no aluno do ensino médio o interesse pelo conhecimento geográfico. (Professor da educação básica 2, 2018. Informação verbal)

Outro aspecto destacado diz respeito à atualização do conhecimento, pois, segundo um dos professores:

[...] à medida que a gente vai para o interior e se distancia da universidade, a gente perde aquela rotina de se atualizar das informações e, aí, a gente vai repetindo [...]. Quando você pega um fascículo desse você se atualiza [...], nos instiga a buscar mais, e nos

\footnotetext{
${ }^{2}$ Disponível em: https://www.lapig.iesa.ufg.br/lapig/

${ }_{3}^{3}$ Disponível em: http://www.Sieg.go.gov.br/rgg/siegdownloads/index.html.
} 
aproximar das questões acadêmicas. (Professor da educação básica 3, 2018. Informação verbal)

No que diz respeito às figuras, segundo os professores, a contribuição está na disponibilidade de mapas de Goiás, assim como a riqueza de detalhes, principalmente nas escalas regional e local. Por meio dos mapas, imagens e informações específicas sobre o estado de Goiás, é possível produzir novos conhecimentos com os estudantes.

Porém, os professores indicaram suas próprias dificuldades em relação aos conteúdos cartográficos e ao uso das geotecnologias no desenvolvimento dos exercícios propostos no material didático. Um exemplo foi dado por uma professora universitária ao usar o material na graduação, afirmando que:

Tiveram dificuldades com os programas e aplicativos [...]. Uns com maior facilidade, outros com mais dificuldade, então emperra mesmo nesta questão tecnológica. As atividades são inovadoras, mas esbarram no uso, de como usar, de ter acesso à ferramenta e saber utilizá-la. Por exemplo, eu não consegui realizar a produção dos mapas, pois uma perspectiva do fascículo é que o próprio aluno seja um mapeador, mas não foi possível.(Professor Universitário 1, 2018. Informação verbal)

Ainda sobre as atividades, os pontos fortes que foram considerados estão na inovação. Os professores reconheceram que as questões estimulam a pesquisa, a compreensão dos fenômenos geográficos e orientam para o uso de diferentes linguagens. Porém, é um dos itens que mereceu maior debate entre eles, sobretudo quanto às dificuldades que tiveram para colocar em prática as sugestões.

Outra ênfase, como sugestão para a revisão do material, diz respeito às questões ambientais e à formação socioespacial de Goiás. Os professores pediram que esses temas fossem mais aprofundados para que houvesse maior compreensão da realidade do estado, porém argumentaram que essa inserção não deveria ampliar os textos, pois sua configuração está num formato que favorece o uso didático. 
Em relação ao uso didático do material e a percepção dos professores quanto à aprendizagem dos estudantes, o que foi mais significativo, segundo eles, foi a aprendizagem sobre o local, sua diversidade cultural, o debate político sobre os movimentos sociais e a complexidade da relação campo e cidade. Esses conhecimentos do local, alicerçados nos conceitos e conteúdos, permitiram a valorização da experiência dos alunos, pois sendo o recorte a escala do estado e/ou dos municípios que o compõem, o professor pode contextualizar os conteúdos que nos livros didáticos convencionais estão na escala nacional e/ou internacional.

O Exame Nacional do Ensino Médio (Enem), realizado pelo governo federal, também privilegia essas escalas, enquanto o estado de Goiás exige, entre o rol dos conteúdos, o ensino do estado de Goiás como componente curricular. Sobre essa questão da abordagem escalar no Ensino de Geografia, vale ressaltar as seguintes preocupações:

[...] para explorar as possibilidades e os limites de abordagens alternativas do ensino presentes no cenário contemporâneo, uma das orientações bastante recorrentes, que é a de se ter como referência o lugar do aluno, e de trabalhar com essa escala de análise como referência para compreender escalas mais amplas [...] indica-se que, ao estudar os temas, deve-se ir do local ao global e deste ao local. Por um lado, há nessas recomendações a preocupação em dar significado aos conteúdos geográficos para o próprio aluno, fazendo ligação mais direta dos conhecimentos trabalhados em sala de aula com seu cotidiano, com sua vida imediata, com a realidade experimentada; por outro lado, nelas também está a ideia de que no lugar é possível encontrar elementos da realidade mais ampla, na compreensão de que nele tem-se a manifestação do global. (CAVALCANTI, 2011, p. 198)

Nesse contexto, o material didático contribui como um meio alternativo para aproximar o conteúdo da vida do aluno na escala do estado e/ou potencializando a abordagem de questões locais de modo a compreender os processos inerentes às relações escalares.

Ainda sobre a escala de abordagem no material didático, os professores indicaram que esse foi o aspecto de maior significado para a sua formação, pois algumas escolas 
recebem alunos que moram no campo ou em cidades que estão longe da capital do estado [Goiânia]. Ou seja, são localidades cuja paisagem evidencia a forte relação com o campo, e, portanto, nem sempre compatíveis com os exemplos dos livros didáticos, que priorizam os conteúdos sobre regiões centrais e metropolitanas, a cidade e o urbano. Dessa maneira, na medida em que o material traz questões do campo e do modo de vida rural, ou mesmo temas culturais, contribui para aproximar o conteúdo da vida do aluno, na escala do estado e/ou potencializando a abordagem de questões locais.

O Currículo de Referência do Estado de Goiás (GOIÁS, 2015) também aponta a importância de se trabalhar a Geografia no ensino médio, de forma que possibilite ao aluno localizar-se e descrever o espaço geográfico, a situar-se e a posicionar-se diante do seu espaço e situações do dia a dia. Posto isso, cabe ao professor de Geografia tomar o lugar do aluno, a escala local, para a compreensão do mundo. Destacam-se, ainda, nesse cenário, a contribuição de várias publicações que foram produzidas nos últimos anos no Brasil, sob a forma de livros, artigos científicos, teses e dissertações, que se referem à importância de se ensinar Geografia nos ensinos fundamental e médio, contemplando essa escala e o cotidiano do aluno como referências para a abordagem dos conceitos e conteúdos em sala de aula (BENTO, 2013; CALLAI, 2009; CAVALCANTI, 2002, 2008, 2013; CASTELLAR, 2009; PIRES, 2013; MENEZES, 2014).

O pressuposto dessas discussões é o de que, refletindo e agindo a respeito dessa realidade, o exercício da cidadania encontra o seu ponto de partida. Paradoxalmente, uma nova proposta curricular para o ensino médio, em implantação, leva a entender que o estudo da Geografia parece perder espaço e relevância no currículo desse nível escolar. Além disso, a indicação do Enem como o parâmetro mais importante para o ingresso dos jovens nas universidades de todo o país, cujo instrumento está centrado em temáticas gerais, coloca em questão as referências mais diretas ao lugar do aluno. Nesse sentido, essas orientações encontram dificuldades de efetivação diante da predominância de uma abordagem generalista, que historicamente tem promovido o desinteresse da Geografia pela vida cotidiana.

Por meio das discussões na roda de conversa com os professores para avaliação do material, foi possível verificar que o seu uso didático levou o professor à necessidade 
de autoria e de recontextualização dos conteúdos. Nesse sentido, se, por um lado, produzir conhecimento próprio expôs uma certa insegurança e até mesmo desconforto, por outro, foi estimulante na medida em que o professor observou o interesse dos alunos pela Geografia, o envolvimento nas temáticas locais e o desafio que é olhar para a própria realidade.

$\mathrm{Na}$ apresentação de trabalhos com o uso do material didático pelos estudantes do ensino médio, por ocasião de um seminário, verificamos que foram realizadas pesquisas locais sobre os mais diferentes temas, tais como: distribuição e logística de acesso à rede de internet; análise ambiental do espaço urbano; gerenciamento de resíduos sólidos etc; e, ao apresentar a pesquisa realizada, bem como as proposições para solucionar os problemas identificados, ficou evidente o uso de conceitos e nomenclaturas geográficas, tais como: cidade e urbano, relação cidade campo, o relevo, cidadania e meio ambiente, dentre outros.

Nesses estudos, os alunos observaram e analisaram a paisagem, realizaram trabalhos de campo para coleta de dados (com aplicação de enquetes, entrevistas e registro de observações e fotos), leram e interpretaram mapas, analisaram legislações locais para conferir normas e as consequências do uso inadequado do solo. Isso indica que houve espaço para ressignificação de informação e dos conhecimentos prévios dos alunos para uma abordagem mais conceitual e significativa. É relevante que, além da compilação, os estudantes realizaram a sistematização e análise dos dados coletados e ensaiaram proposições. Embora também tenha sido perceptível a dificuldade de alguns deles, sobretudo naquelas escolas com menos infraestrutura, o uso do material com o olhar para a sua localidade e/ou região demonstrou ser muito relevante para os envolvidos.

Além da experimentação do material didático, outra dimensão importante da investigação diz respeito à formação da equipe no processo de sua elaboração, experimentação e avaliação. Percebeu-se que o processo é muito educativo em vários aspectos, com destaque para a contribuição à produção de conhecimentos conceituais, didáticos e locais, à atuação profissional (professores da educação básica e universitários) e à colaboração entre níveis de formação (estudante de graduação, pós-graduação e 
pesquisadores). Se, para os professores universitários, a atualização dos conhecimentos e aprendizagem de novas linguagens foi o mais marcante, para os estudantes de graduação a contribuição em relação aos conhecimentos adquiridos esteve na aprendizagem da Geografia: seus conceitos e metodologias de ensino, suas linguagens e até mesmo a abordagem metodológica desse campo. Para um deles, a participação permitiu:

[...] a construção de conceitos geográficos: ao se pensar em como tal conteúdo auxiliaria na construção desses conceitos; práticas cidadãs: através da leitura de textos; Organização de materiais didáticos: com a elaboração do fascículo produzido; Planejamento e condução das aulas através das observações das aulas. (Estudante de graduação 2, 2018. Fonte: Questionário)

Essas dimensões apresentadas pelos professores universitários e estudantes de graduação também apareceram nos registros dos estudantes de pós-graduação.

Em relação à didática e aos conhecimentos locais, o que mais chamou a atenção da equipe foi a potencialidade dialógica que os conteúdos e as atividades propostos no material didático possuem. Nesse sentido, foi consenso que a contextualização dos temas ligados à escala regional e local possibilita a valorização da experiência dos alunos e a formação política. A contribuição entre os diferentes níveis de ensino também foi um aspecto muito forte de todo o processo, com ênfase na formação permanente que a relação universidade-escola potencializa, além das habilidades adquiridas nos trabalhos em grupo. Conforme um professor da universidade, a experiência coletiva possibilitou:

Desenvolvimento de postura aberta aos diversos entendimentos e percepções; firmeza nas leituras e análises das temáticas tendo em vista uma sólida formação teórico-conceitual; desenvolvimento de ambiente alegre e agradável para ler, discutir, propor, avaliar e experimentar. (Professor universitário 2, 2018. Fonte: Questionário)

Outro aspecto bastante ressaltado nos momentos de avaliação diz respeito ao conhecimento dos desafios profissionais, como relatado por um professor da educação básica, ao tratar da relação universidade-escola: 
Enquanto propositora de tema e conteúdos no processo de ensino e aprendizagem, a relação só se completa com a prática do conteúdo no espaço escolar. O desafio do professor buscar soluções e possibilidades de ensino é um profícuo movimento de capacitação e desenvolvimento. Sua efetividade depende da coesão e diálogo entre os diferentes sujeitos/instituições. (Professor da educação básica 1, 2018. Fonte: Questionário)

Pelo exposto, de modo geral, a equipe percebeu que o processo foi significativo do ponto de vista da formação e que o projeto reforça a capacitação da instituição escola, beneficiando-se da relação com a universidade, nos seguintes aspectos: 1) Com as escolas diretamente envolvidas no projeto por meio da participação na produção do material didático, com a atualização de referencial teórico-metodológico e com a disponibilização do próprio material; 2) Com a produção do material didático que fica disponível para as demais escolas da rede pública de ensino do estado de Goiás.

Vale destacar que, nesse processo de formação inicial e continuada do professor de Geografia, a pesquisa colaborativa concebe que o professor é um sujeito social e tem um importante papel político e que é fundamental refletir sobre o sentido do conhecimento produzido para a escola, para a educação e para o desenvolvimento da sociedade que se deseja. Considera-se que, nessa sociedade, a função do professor é lidar com as diferenças e desigualdades presentes no cotidiano, bem como lidar com os conflitos sociais no interior da escola e na sala de aula. Defende-se, por fim, que para lidar com as contradições inerentes à atividade profissional que o professor desempenha, é fundamental possuir conhecimentos geográficos e pedagógico-didáticos consistentes.

\section{Considerações finais}

A pesquisa crítico-colaborativa para formação inicial e continuada de professor de Geografia efetivada no contexto de produção, acompanhamento e utilização de materiais didáticos sobre A relação Cidade/Campo no Território Goiano, mostrou sua contribuição significativa para a prática profissional do professor na efetivação de práticas de ensino 
mais significativas no ensino médio, ao passo que também é significativa na formação geográfica dos alunos nesse nível de ensino.

No processo de construção do material didático, houve também a formação de estudantes de graduação e de pós-graduação dos cursos de Geografia que atuam diretamente nos diferentes grupos constituídos para a realização das pesquisas propostas por essa Rede. Essa formação ocorreu seja por meio da aprendizagem do arcabouço teórico-metodológico da área, seja pela aproximação com a educação básica, ainda no processo de formação inicial, seja, ainda, pela troca de experiência intergeracional envolvida nas ações, na medida em que se integraram profissionais, de diferentes níveis de ensino, desse modo aproximando a formação inicial e continuada.

O estabelecimento de intercâmbio mais sistemático entre a Universidade Federal de Goiás via curso de Geografia, a Universidade Estadual de Goiás e as Redes Públicas de Ensino Médio do Estado de Goiás, vivenciado no processo de produção, experimentação e avaliação do material didático, demonstrou a importância do trabalho integrado e interinstitucional para pensar ações efetivas para a melhoria da educação básica.

O protagonismo dos professores da educação básica no conjunto do processo e na avaliação do material evidenciou a valorização profissional e o significado positivo das ações colaborativas também para o seu reconhecimento.

A participação colaborativa no conjunto de ações permitiu aos envolvidos um conhecimento mais autoral. Essa autoria foi propiciada pela aproximação entre universidade e escola para enfrentar os desafios formativos e o desenvolvimento de metodologias, com a ênfase no protagonismo dos estudantes e na valorização dos seus contextos de vida.

Os próprios materiais didáticos regionais e locais são importantes na produção de conhecimento sobre os territórios nessas escalas e preenchem uma lacuna, sem, com isso, substituírem o livro didático, tampouco outras bibliografias acessadas pelos professores na sua prática profissional.

Acredita-se, portanto, que o desenvolvimento desse tipo de ação colaborativa é um caminho possível para aprimorar o trabalho docente, apresentar dimensões 
importantes para a Didática em Geografia e, por sua vez, estreitar os vínculos entre os professores da escola com a produção acadêmica. Ademais, contribui com o desenvolvimento das pesquisas no ensino de geografia e a formação dos professores capazes de efetivar seu protagonismo na Educação Básica.

Com a investigação colaborativa em um processo formativo é possível a construção de conhecimentos, fruto de ações dinâmicas, polifônicas, multidimensionais, dialógicas e interacionistas, em que a realidade imediata e os conhecimentos científicos se entrecruzam e possibilitam significações mais efetivas do conhecimento produzido.

\section{Referências}

\section{BENTO, Izabella Peracini. A mediação didática na construção do conhecimento} geográfico: uma análise do processo de ensino e aprendizagem de jovens do ensino médio e da potencialidade do lugar. 2013. Tese. (Doutorado em Geografia) - INSTITUTO DE ESTUDOS SOCIOAMBIENTAIS - IESA, Universidade Federal de Goiás, Goiânia, 2013.

CALLAI, Helena Copetti. O lugar e o ensino aprendizagem de geografia. In: GARRIDO, Marcelo (org.). La espesura del lugar: reflexiones sobre el espacio en el mundo escolar. 1ed. Santiago: Ediciones Universidad Academia de Humanismo Cristiano, 2009. v. 1. p. 171190.

CASTELLAR, Sônia Maria Vanzella. Lugar de vivência: a cidade e a aprendizagem. In: GARRIDO, Marcelo. (org.). Reflexiones sobre el espacio en el mundo educativo. 1ed. Santiago: Ediciones Universidad Academia de Humanismo Cristiano, 2009. p. 37-56.

CAVALCANTI, Lana de Souza; OLIVEIRA, Karla Annyelly Teixeira de; SPIRONELLO, Rosangela Lurdes (org.). A relação cidade/campo no territorio goiano. 3. Ed. Goiânia: C\&A Alfa de comunicação, 2020.

CAVALCANTI, Lana de Souza. Geografia escolar e a busca de abordagens teórico/práticas para realizar sua relevância social. In: SILVA, Eunice Isaías da; PIRES, Lucineide Mendes.

CAVALCANTI, Lana de Souza. O ensino de geografia na escola. Campinas-SP: Papirus, 2012.

CAVALCANTI, Lana de Souza. Ensinar geografia para a autonomia do pensamento: o desafio de superar dualismos pelo pensamento teórico crítico. Revista da ANPEGE, v. 7, n. 1, p. 193-203, out. 2011. Número especial. 
CAVALCANTI, L. de S. Formação inicial e continuada em geografia: trabalho pedagógico, metodologias e (re)construção do conhecimento. In: ZANATTA, Beatriz Aparecida; SOUZA, Vanilton Camilo (orgs.) Formação de professores: reflexões do atual cenário sobre o ensino da Geografia. Goiânia: NEPEG/Vieira, 2008.

CAVALCANTI, L. de S. Bases teórico-metodológicas da geografia: uma referencia para formação e a prática de ensino. In: CAVALCANTI, L. de S. Formação de profesores: concepções e práticas em geografia. Goiânia: Vieira, 2006.

CAVALCANTI, L. de S. Geografia e práticas de ensino. Goiânia: Alternativa, 2002.

CUNHA, M. S. de C. Trajetórias e lugares de formação da docência universitária: da perspectiva individual ao espaço institucional. Brasília, DF: CAPES/CNPq, 2010.

Estudante de graduação 2. Fonte: Questionário respondido a equipe da REPEC no Seminário de Avaliação da REPEC: Uso e prática do fascículo pedagógico em sala de aula, em 04 de dezembro de 2018.

FRANCO, Maria Amélia Santoro; PIMENTA, Selma Garrido (org.). Pesquisa em Educação: possibilidades investigativo-formativas da pesquisa-ação. 2. ed. São Paulo: Loyola, 2010.

GARCÍA PÉREZ, F. F. Formación del profesorado y realidades educativas: una perspectiva centrada en los problemas prácticos profesionales. In: ESCUDERO, J. M.; LUIS, A. (eds.). La formación del profesorado y la mejora de la educación: políticas y prácticas. Barcelona: Octaedro, 2006. p. 269-309.

GARCÍA PÉREZ, F. F. Un modelo didáctico alternativo para transformar la educación: el modelo de investigación en la escuela. Scripta Nova: Revista Electrónica de Geografía y Ciencias Sociales, Barcelona: Universidad de Barcelona, v. 15, n. 64, 2000. Disponível em: https://revistes.ub.edu/index.php/ScriptaNova/article/view/193. Acesso em 15 janeiro de 2020.

GOIÁS. Secretaria de Estado da Educação. Currículo referência da rede estadual de educação de goiás Goiânia: [s.n.], 2012. (versão experimental). Disponível em: https://site.educacao.go.gov.br/wp-content/uploads/2019/04/CurriculoReferencia.pdf. Acesso em: 13 jan 2019.

IBIAPINA, I. M. L. de M. Pesquisa colaborativa, investigação, formação e produção de conhecimentos. São Paulo: Liber Livros, 2008.

IMBERNÓN, Francisco. Formação docente e profissional: formar-se para a mudança e incerteza. São Paulo: Cortez, 2017. 
LUDKE, Menga. A complexa relação entre o professor e a pesquisa. In: ANDRÉ, Marli. 0 papel da pesquisa na formação e na prática dos professores. Campinas: Papirus, 2001.

MENEZES, P. K. Ser jovem, ser estudante, ser do campo: a concepção de rural e urbano para jovens estudantes em escolas públicas das cidades de Goiânia e Trindade. 2014. Dissertação. (Mestrado em Geografia) - Instituto de Estudos Socioambientais - IESA, UFG, Goiânia, 2014.

PIRES, L. M. Culturas geográficas de alunos-jovens: uma referência para a formação de professores de Geografia. 2013. Tese (Doutorado em Geografia), Instituto de Estudos Socioambientais - IESA, Universidade Federal de Goiás, Goiânia, 2013.

PORLÁN ARIZA, Rafael; RIVERO, Ana. El conocimiento de los profesores. Sevilla: Diada Editora, 1998.

Professor da educação básica 2 [Informação verbal cedida a] Equipe da REPEC no Seminário de Avaliação da REPEC: Uso e prática do fascículo pedagógico em sala de aula, em 04 de dezembro de 2018.

Professor da educação básica 3 [Informação verbal cedida a] Equipe da REPEC no Seminário de Avaliação da REPEC: Uso e prática do fascículo pedagógico em sala de aula, em 04 de dezembro de 2018.

Professor Universitário 1. [Informação verbal cedida a] equipe da REPEC no Seminário de Avaliação da REPEC: Uso e prática do fascículo pedagógico em sala de aula, em 04 de dezembro de 2018.

Professor universitário 2. Fonte: Questionário respondido a equipe da REPEC no Seminário de Avaliação da REPEC: Uso e prática do fascículo pedagógico em sala de aula, em 04 de dezembro de 2018.

Professor da educação básica 1. Fonte: Questionário respondido a equipe da REPEC no Seminário de Avaliação da REPEC: Uso e prática do fascículo pedagógico em sala de aula, em 04 de dezembro de 2018.

SHULMAN, Lee S. Conocimiento y ensenanza: fudamentos de la nueva reforma. Revista de currículum y formación del profesorado, Granada: Universidad de Granada, n 09, v.02, p. 1-30, 2005.

TRAVÉ, Gabriel; CAÑAL, Pedro; POZUELO, Francisco J. Aportaciones de proyecto curricular investigando nuestro mundo (6-12) al cambio en La educación primaria. Investigación en La Escuela, Sevilla, n. 51, p. 6-12, jun. 2003. 
Recebido em: 11/07/2019 Aprovado em: 27/07/2020

Universidade do Estado de Santa Catarina - UDESC Centro de Ciências Humanas e da Educação - FAED

Revista PerCursos

Volume 21 - Número 46 - Ano 2020 revistapercursos@gmail.com 